\title{
Kaasava hariduse mudel alushariduse kontekstis: süstemaatiline kirjandusülevaade
}

\author{
Pille Nelis $^{\mathrm{a}}$, Margus Pedaste ${ }^{\mathrm{a}}$ \\ ${ }^{a}$ Tartu Ülikooli haridusteaduste instituut
}

\begin{abstract}
Annotatsioon
Hoolimata suurest hulgas maailmas korraldatud uuringutest ei ole kaasava hariduse kontseptsioon edukaks rakendamiseks piisavalt selge. Seetõttu tegime süstemaatilise kirjandusanalüüsi, et luua ülevaade kaasava hariduse definitsioonidest ja võtmetunnustest, mis toetaks selle rakendamist alushariduse tasemel. Selgus, et kaasava hariduse definitsioonis tuleks eristada selle filosoofilist ja praktilist olemust, mida kirjeldavad täpsemalt seitse aspekti. Nüüdisaegse kaasava hariduse rakendamisel olulised võtmetunnused alushariduse kontekstis on süstematiseeritavad 14 kategooria kaudu viiel tasandil: lapse, perekonna, õpetaja, institutsiooni ja riigi tasand. Definitsiooni ja võtmetunnuste alusel loodi mudel, millega toetada kaasava hariduse rakendamist eri poolte koostöös.
\end{abstract}

Võtmesõnad: kaasav haridus, alusharidus, koolieelne lasteasutus, definitsioon, süstemaatiline kirjandusanalüüs

\section{Sissejuhatus}

Kaasava hariduse idee ja selle rakendamine on kujunenud viimastel aastakümnetel maailmas haridusvaldkonna üheks võtmeküsimuseks (Soukakou, 2012; Soukakou, Evangelou, \& Holbrooke, 2018; Vlachau \& Fyssa, 2016). Kaasamine on muutunud prioriteediks rahvusvahelistes haridusstrateegiates ja -poliitikas, sealhulgas alushariduse valdkonnas (European Commission, 2014; OECD, 2001; UNESCO, 2008). Paljud uuringud on näidanud, et alusharidus kaasavas õpikeskkonnas avaldab pikaajalist ja positiivset mõju laste akadeemilistele oskustele, sotsiaalsele arengule ja edasijõudmisele koolis (Kwon, Hong, \& Jeon, 2017; Odom, 2002; Odom, Buysse, \& Soukakou, 2011; OECD, 2018a; Vlachau \& Fyssa, 2016). Kwon jt (2017) toovad oma artiklis välja kaasava keskkonna positiivse mõju ka tavapäraselt arenenud lastele. Nimelt aitab see kujundada nende suhtumist erinevustesse ja mõista paremini erivajadustega laste olukorda. Selle tulemusena õpivad lapsed suhtlema ja looma suhteid mitmesuguste inimestega. Seejuures on võtmeteguriks kaasamise ja koolieelse

Haridusteaduste instituut, Tartu Ülikool, Salme 1a, 50103 Tartu; pille.nelis@ut.ee. 
hariduse kvaliteet (European Commission, 2014; OECD, 2012; Soukakou et al., 2018).

Kaasava hariduse rakendamise kvaliteediga seotud uuringutes on kesksel kohal arutelu kaasava hariduse mõiste ja sisu määratlemise üle (Fyssa, Vlachou, \& Avramidis, 2014; Næsby, 2018; Warren, Martinez, \& Sortino, 2016). Üldiselt mõistetakse 1994. aasta Salamanca deklaratsiooni kohaselt kaasavat haridust kui juurdepääsu õppimisvõimalustele, mis toetavad kõigi laste õigust osaleda aktiivselt hariduses ja oma kogukonna igapäevastes tegevustes sõltumata erivajadusest (Prater, 2010; Sukumaran, Loveridge, \& Green, 2015; UNESCO, 2008). Kirjanduses esineb definitsioone, kus autorid rõhutavad kaasava hariduse eri aspekte (Kivirand, Leijen, Lepp, \& Malva, 2020). Näiteks defineeritakse seda kui lapse õigust osaleda hariduses koos tavapäraselt arenenud lastega (Hoskin, Boyle, \& Anderson, 2015; Lawrence, Smith, \& Banerjee 2016) või haridussüsteemi osa, kus õpikeskkond, õpetaja tegevus ja tugisüsteem tagavad iga lapse arengu (Kwon et al., 2017; Pelatti, Dynia, Logan, Justice, \& Kaderavek, 2016; Warren et al., 2016). Definitsioonide ja arusaamade süstematiseerimine ja selle üle arutlemine toetab kaasava hariduse põhimõtete rakendamist (Florian, 2017).

Kuna kaasav haridus sisaldab endas mitmeid tahke, mis seda mõjutavad, võib kaasavat haridust rakendada väga erinevalt (Haug, 2017; Prater, 2010). Häidkind ja Oras (2016) leidsid oma uuringus, et Eesti õpetaja jaoks seostub kaasav haridus eeskätt kõikide laste koos õpetamise ja individuaalse lähenemisviisiga, mille juures peeti oluliseks tugisüsteemi rolli ning koostööd perekonnaga. Kaasamine võib erineda nii riikide vahel kui ka riigi sees sõltuvalt kultuurilisest, poliitilisest, sotsiaalsest ja majanduslikust kontekstist ja võimalustest (Hu, Roberts, Wang, \& Zhao, 2011; Næsby, 2018; Sukumaran et al., 2015) ning kaasamise mõistest arusaamisest ja selle tõlgendamisest (Stone, 2014; Sukumaran et al., 2015).

Kirjanduse andmetel on kaasava hariduse edukal rakendamisel võtmetunnused, millele peaksid tegevused vastama. Varasemates uuringutes on püütud kaasava hariduse võtmetunnuseid mitmeti süstematiseerida ja esitada. Bronfenbrenneri ja tema kolleegide arendatud bioökoloogiline mudel on laialt levinud kaasava hariduse võtmetunnuste kirjeldamisel ja esitamisel (Love, 2018; Næsby, 2018; Odom et al., 1999, 2004). Bronfenbrenneri sõnul mõjutab ümbritsev keskkond lapse arengut ja kasvamist. Bioökoloogilises mudelis rõhutatakse lapse tähtsust mitme keskkonna ehk süsteemi kontekstis ja mudeli keskmes on biosüsteem ehk laps ja lapse erivajadused, mis on mõjutatud eri süsteemidest. Mudelis esitatakse kaasava hariduse võtmetunnused nende süsteemide kaupa: mikro-, meso-, ekso-, makro- ja kronosüsteem. Mikrosüsteem on lapse lähim ümbrus ja keskkond, kus laps ise aktiivselt osaleb: 
kodu ja lasteaed. Mesosüsteemi iseloomustavad mõjutused mikrosüsteemi eri osade vahel, näiteks õpetaja ja lapsevanemate ning õpetajate omavaheline koostöö. Eksosüsteem koosneb mõjutustest või sündmustest, mis mõjutavad mikrosüsteemi, kuid toimuvad sellest väljaspool, näiteks haridus- ja sotsiaalpoliitika ning juhtimine. Makrosüsteem hõlmab laiema sotsiaalse, poliitilise ja kultuurilise konteksti tegureid, mis mõjutavad süsteemi teisi tasandeid, näiteks üldine ideoloogia, põhiväärtused ja kultuuritraditsioonid. Kronosüsteem tähistab muutusi aja jooksul igal süsteemitasandil. Mudeli peamine tähendus seisneb selles, et süsteemi iga tasandi tunnused mõjutavad tunnuseid teistel tasanditel ja on omakorda mõjutatud teiste tasandite tunnuste poolt (Odom, 2002). Bioökoloogiline mudel on küll laialdaselt levinud, kuid lisaks sellele leidub alushariduses kaasava hariduse võtmetunnuste süstematiseerimisel ka teisi lähenemisi.

Paljud autorid ja mõned rahvusvahelised organisatsioonid (European Agency for Special Needs and Inclusive Education, 2017; Fyssa et al., 2014; Pealtti et al., 2017) on võtmetunnuste kirjeldamisel kasutanud kahedimensioonilist lähenemist: struktuursed tunnused (nt õpetajate erialane ettevalmistus ja professionaalne areng, laste arv rühmas, õpetaja ja laste suhtarv, rahastamine) ja protsessi tunnused (nt emotsionaalne tugi, sotsiaalne suhtlus, õpikeskkond ja õpetamine), mis mõlemad on olulised aspektid kaasava hariduse rakendamisel. Mõned uuringud toovad välja sellised tunnused nagu ressursid, materjalidega varustatus, koolitus, juurdepääs haridusele, osalemine tavarühmas ja tugisüsteem, viidates neile tunnustele kui kaasava hariduse kvaliteediga seotud teguritele (Chhabra, Bose, \& Chadha, 2018; National Early Childhood Technical Assistance Center, 2011; Pelatti et al., 2016). Seega on kaasava hariduse võtmetunnuste süstematiseerimiseks mitmesuguseid viise ja vajab analüüsimist, kuidas seda tuleks teha nii, et süsteem hõlmaks definitsiooni ja kõiki võtmetunnuseid.

Uuritava teema käsitlemist erinevates uuringutes aitab kõige paremini näha süstemaatiline kirjandusülevaade (Alexander, 2020). Vaadates läbi andmebaasis Web of Science kajastuvate süstemaatilisi kirjandusülevaateid ja metaanalüüse avaldavate kõige mõjukamate haridusalaste teadusajakirjade (Review of Educational Research, Educational Research Review) artiklite pealkirjad, leiti vaid mõned kaasava haridusega seotud ülevaateartiklid. Lisaks vaadati läbi kaasava hariduse valdkonna ühe juhtivajakirja (International Journal of Inclusive Education) kõigi artiklite pealkirjad, et leida süstemaatilist kirjandusanalüüsi või metaanalüüsi sisaldavaid artikleid. Enamik avaldatud süstemaatilise kirjanduse ja metaanalüüsi artikleid olid seotud kooliga (de Jager, 2013; Harrison, Soares, \& Joyce, 2019; O’Rourke \& John, 2015; Stepaniuk, 2019). Mõned osaliselt alusharidusega seotud artiklid käsitlesid kaasavat 
haridust nii koolieelsel kui ka kooli tasandil üldiselt ja keskendusid kas konkreetse erivajadusega lapse toetamisele (nt autism, sotsiaal-emotsionaalsed ja käitumisraskused) (Botha \& Kourkoutas, 2016; Gaffney \& Wilkins, 2016) või ühele lähenemisviisile kaasava hariduse rakendamise toetamiseks, näiteks Universal Design for Learning (Capp, 2017), kaasava hariduse ühele kitsale aspektile, näiteks sotsiaalne aspekt (Bossaert, Colpin, Pijl, \& Petry, 2013; Schneider, 2015) või kaasava hariduse rakendamisele ühe riigi kontekstis (Loreman, 2014). Seega on küll ka varem tehtud süstemaatilisi kirjandusanalüüse kaasava hariduse kohta, kuid enamik neist keskendub kooli kontekstile. Üksikud artiklid on kaudselt seotud alushariduse valdkonnaga, kuid keskenduvad kaasava hariduse mõnele kitsamale aspektile. Kaasava hariduse olemusele või selle rakendamisele keskenduvaid alushariduse kontekstis tehtud süstemaatilisi kirjandusülevaateid ja metaanalüüse ei leitud. Samas ei saa kaasavat haridust koolieelses lasteasutuses ja koolis täpselt ühtmoodi käsitleda. Häidkind ja Oras (2016) leidsid, et lasteaiaõpetajate individuaalne arusaam kaasavast haridusest erineb kooliõpetajate omast. Kui lasteaiaõpetaja jaoks tähendab kaasav haridus erivajadustega laste ja tavalaste õpetamist koos ühes rühmas, siis kooliõpetaja näeb, et lapsi võib õpetada nii ühes klassis kui ka ühes koolis ehk siiski eraldatult eraldi klassis. Samuti peegelduvad erinevused lasteaiaõpetajate ja kooliõpetajate hoiakutes kaasava hariduse suhtes, mida võib seletada õppijate, personali ja keskkonna erisustega (Häidkind \& Oras, 2016).

Seega puuduvad alushariduses kaasava hariduse definitsioonide ja võtmetunnuste kohta süstemaatilised kirjandusülevaated, mis aitaks mõista kaasava hariduse olemust selle kõigis aspektides, toetaks kaasava hariduse rakendamist ning annaks aluse kaasava hariduse võrdlemiseks eri kontekstides. Seetõttu on oluline välja selgitada kaasava hariduse kõiki aspekte hõlmav definitsioon ja võtmetunnused. Siinse artikli eesmärk on pakkuda definitsioon, mis lõimiks kirjanduses leiduvate definitsioonide kõige olulisemad aspektid ja sisaldaks nüüdisaegse kaasava hariduse võtmetunnuseid ning võimaldaks välja töötada raamistiku kaasava hariduse rakendamiseks alushariduses. Eesmärgi saavutamiseks tehti süstemaatiline kirjandusanalüüs, mille tulemused aitaks kaasava hariduse rakendamisel otsuseid teha. Täpsemalt seati töös kaks alaeesmärki:

1) Defineerida kaasav haridus, tuginedes mitmesugustele kaasava hariduse käsitlustele alushariduses.

2) Koostada kaasava hariduse alushariduse tasemel rakendamiseks sobiv võtmetunnuste raamistik. 


\section{Metoodika}

Töö eesmärkide saavutamiseks tuli koondada ja analüüsida eri uuringute tulemused ja seetõttu kasutati süstemaatilist kirjandusanalüüsi, mis võimaldab analüüsida ja sünteesida teaduskirjandust loogilisel, läbipaistval, arusaadaval ja analüütilisel viisil. Samuti aitab see tuua välja sarnasused ja erinevused, kirjeldada tunnuseid ning leida uuringuid läbivaid seaduspärasusi ja trende (Alexander, 2020), mis võimaldaks siinses uuringus esitada üldistavalt kaasava hariduse definitsiooni ja võtmetunnused ning koostada nende alusel mudeli kaasava hariduse rakendamise toetamiseks.

\section{Andmekogumine}

Allikate otsinguks kasutati EBSCOhost'i teenuse kaudu eri andmebaase (vt joonis 1). Otsingu märksõnad olid inclusive education OR inclusion $O R$ inclusive settings AND early childhood education OR preschool OR kindergarten OR early years AND characteristics OR activities OR framework OR dimension OR components OR principles OR intervention OR profile OR structure. Dubleeringute eemaldamisel jäi alles 423 allikat, mille annotatsioonide vastavust uuringu eesmärkidele hinnati (vt joonist 1). Allikate uuringusse võtmise kriteeriume oli kaks: 1) teave; artikkel annab teavet kaasava hariduse tunnuste, tegevuste või raamistike kohta ja 2) kontekst; artikkel on seotud alusharidusega. Edasisse analüüsi haarati vaid allikad, mille puhul oli juurdepääs terviktekstile. Seetõttu jäeti välja raamatud, väitekirjade lühitutvustused, raamatute kokkuvõtted ja raportite lühikokkuvõtted.

Uuringu usaldusväärsuse tagamiseks hindasid kaks uurijat esimese otsinguga leitud allikate annotatsioone. Eesmärgiks võeti hinnata koos vähemalt $10 \%$ allikate annotatsioone kogu allikate hulgast, st 58 allika annotatsioone. Annotatsioonid vaadati läbi ja hinnati nimetatud kahe kriteeriumi alusel. Seejärel leiti hindajatevaheline kooskõla Coheni kaalutud kappa põhjal, mille väärtuseks oli 0,682 . See näitab olulist kooskõla kahe hindaja vahel. Hindajate erinevad arvamused arutati läbi, kuni jõuti ühisele arusaamisele, kas võtta artikkel edasisse analüüsi.

Täistekstide analüüsimisel jäeti välja artiklid, mis keskendusid: 1) ühele erivajadusele (nt autismispektri häire, nägemiskahjustus); 2) kaasamise ühele konkreetsele aspektile (nt kultuuriline mitmekesisus, kakskeelsed õpilased); 3) ühele konkreetsele lähenemisele kaasava hariduse rakendamisel (nt lasteaiaaasta kordamine, muusika kasutamine); 4) kõrgemale haridustasemele (nt algkool, põhikool); 5) teistele valdkondadele (nt keemia, poliitika) ja 6) muudele tunnustele, mis viitasid selgelt, et artikkel ei anna olulist teavet siinse uuringu 
eesmärkide saavutamiseks: óppekavade väljatöötamine, laste kaasamine oma õpikeskkonna parandamisse, lastevanemate vaade, õpetajate hoiakud. Nende kriteeriumide järgimisel võeti edasisse analüüsi 55 artiklit.

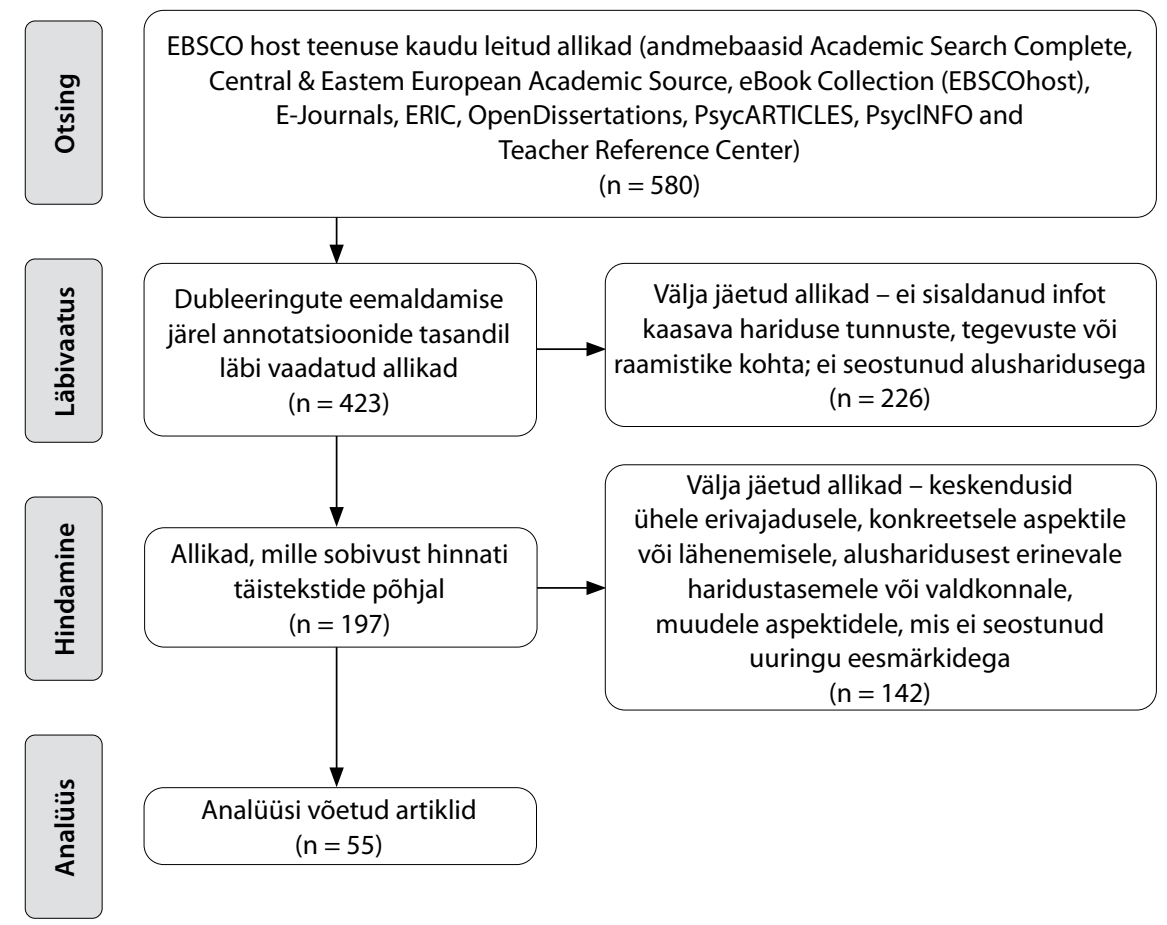

Joonis 1. Allikate süstemaatilise valiku protsessi skeem.

\section{Analüüsi protsess}

Analüüsi võetud 55 allikat kodeeriti ja analüüsiti uurimisküsimuste põhjal: 1) kirjanduses kasutatud kaasava hariduse määratlemise definitsioonid ja 2) kaasava hariduse võtmetunnused. Artiklite analüüsiks kasutati kvalitatiivse induktiivse sisuanalüüsi meetodit. See on analüüsimeetod, mis toimub mitmes etapis kindlaid analüüsireegleid järgides ja kus süstematiseeritud kategooriateni jõutakse analüüsitava teksti enda põhjal (Mayring, 2014). Analüüsi esimeses etapis luges üks uurija artikleid ja leidis tekstist tähenduslikke üksusi. Tähenduslikeks üksusteks olid sõnad, fraasid, laused või lausete kogumid, mis sisaldasid kaasava hariduse definitsioone ja kaasava hariduse tunnuseid. Tähenduslikele üksustele anti nimetused ehk koodid. Teises etapis sarnase sisuga koodid liideti ja tekitati kategooriad. Selleks pöörduti allikate juurde korduvalt tagasi, et olla kindel tähenduslike üksuste sobivasse konteksti paigutamises. Kolmandas etapis koondati sarnased kategooriad suurematesse 
peakategooriatesse, mis kirjeldaksid kaasava hariduse definitsiooni või võtmetunnuste dimensioone. Sarnast skeemi kasutati mõlema uurimisküsimuse juures. Mõlema uurimisküsimuse puhul tekkisid esialgu alakategooriad ja lõpliku analüüsi tulemusel moodustati alakategooriatest peakategooriad ehk dimensioonid (vt http://sisu.ut.ee/kaasavharidus/).

\section{Tulemused}

\section{Kaasava hariduse definitsioon alushariduses}

Analüüsitud 55 artiklist oli kaasava hariduse definitsioon esitatud 41 juhul. Nendes kajastuvaid aspekte on võimalik süstematiseerida Lundqvisti, Mara ja Siljehagi (2015) esitatud viisil, milles eristatakse kaasava hariduse filosoofilist ja praktilist olemust. See jaotus sobitub siinse uuringu tulemustega ja seetõttu kasutatakse kaasava hariduse määratlemisel samuti kahte dimensiooni - filosoofiline ja praktiline olemus. Filosoofilise olemuse all mõeldakse kaasamise väärtustamist, uskumusi ja lähenemist, mis väljendub kultuuris, otsustes ja valikutes haridussüsteemi kõigil tasanditel. Praktiline olemus tähendab tegevusi ja praktilisi rakendusi, mis soodustavad kaasamist.

Kaasava hariduse filosoofilist olemust selgitavad täpsemalt neli aspekti (kategooriat).

1) Juurdepääs haridusele tähendab analüüsitud artiklite põhjal kaasavat haridust, kus erinevused on väärtustatud ja kõigile lastele võimaldatakse hariduse kättesaadavus. See on võrdne võimalus õppida ja areneda tavapärases keskkonnas.

2) Inimõigused hõlmavad olenemata erivajadustest iga lapse ja tema perekonna õigust osaleda ühiskonna täieõigusliku liikmena kogukondade tegevustes ja õigust osaleda alushariduses ja olla kaasatud tavarühma koos eakaaslastega.

3) Kuuluvustunne tähendab analüüsitud allikate kohaselt ühtekuuluvustunde tekitamist, kus erivajadustega lapsega arvestatakse ühtviisi nii perekonnas, kogukonnas kui ka ühiskonnas kui täisväärtusliku ja võrdse liikmega.

4) Sotsiaalset integratsiooni kirjeldatakse kui positiivset sotsiaalset suhet ja sõprussuhteid eakaaslaste vahel, mis tugevdavad suhteid eakaaslaste ja ühiskonna teiste liikmetega ja tekitavad sotsiaalset ühtekuuluvust.

Kaasava hariduse praktilist olemust võib täpsemalt kirjeldada kolme aspekti kaudu.

1) Osalemine tähendab tulenevalt analüüsist kõigi laste füüsilist paigutamist tavarühma või koolieelsesse lasteasutusse, sõltumata individuaalsetest 
erinevustest. Erivajadusega lapsed osalevad õppe- ja kasvatustegevuses ja mängudes koos tavapäraselt arenenud lastega, kus keskkond võimaldab mitmekesiseid tegevusi ja selle kohandamist viisil, mis soodustab kõigi laste aktiivset ja mõtestatud osalemist. Täiskasvanud toetavad õppimist, kasutades individualiseeritud juhendamist ning kohandusi õpivaras, lähtudes lapse vajadustest eesmärgiga innustada kõigi laste osalemist nii mängus kui ka õppe- ja kasvatustegevuses.

2) Tugisüsteem viitab piisava infrastruktuuri ja tugisüsteemide olemasolule, sealhulgas perede toetamisele. Kirjanduses tuuakse välja, et tugisüsteem hõlmab ka kaasamise edendamise strateegiat alushariduses. Selle all mõeldakse pedagoogilist lähenemisviisi või õpikäsitust, mis võimaldab kõigile lastele võimetekohase hariduse. Õpikäsitus ja põhimõtted õppekavas toetavad strateegia järgimist. Veel tuuakse kirjanduses välja laste õppimist toetavad tegevused rühmaruumis: tegevuste ja juhendamise kohandamine viisil, mis soodustab aktiivset osalemist õppe- ja kasvatustegevuses, ja tuge, mis võib erineda tulenevalt laste vajadustest. Tugisüsteemide all mõeldakse ka, et kõigil täiskasvanutel, kes on osalised kaasava hariduse rakendamisel, on võimalus professionaalseks enesearenguks.

3) Lapse areng tähendab kirjanduse põhjal, et laste arengut edendatakse iga lapse potentsiaaliga maksimaalselt arvestades nii, et saavutatakse individuaalsed õpieesmärgid. Siin on oluline, et iga laps kogeb eduelamust ja saab õppimisest positiivseid emotsioone.

Põhjalikumalt on kaasava hariduse nii filosoofiline kui ka praktiline olemus avatud veebilehel http://sisu.ut.ee/kaasavharidus/.

Eelnevale süstemaatilisele kirjandusanalüüsile tuginedes võime sõnastada kaasava hariduse definitsiooni alushariduse kontekstis: kaasavaks hariduseks nimetatakse inimõigusi arvestavat ja heale haridusele ligipääsu võimaldavat lähenemisviisi, kus lapsed tajuvad sotsiaalset integratsiooni ja kuuluvustunnet laiemas sotsiaalses võrgustikus, hoolimata nende erivajadustest, ning kaasamine saavutatakse laste aktiivse mõtestatud osaluse ja personaalse lähenemise kaudu lapse arengu toetamisel tema täielikku potentsiaali arvestades.

Selle definitsiooni lahtimõtestamisel võib esiteks välja tuua, et kaasav haridus on lähenemisviis. Teiseks on selle järgi oluline, et kaasava hariduse subjektiks on lapsed, kes ennast teatud viisil tajuvad ja kelle potentsiaali saavutamine on eesmärgiks. Kolmandaks viitab see meetoditele, millega lähenemisviis, taju ja potentsiaal saavutatakse - aktiivne mõtestatud osalemine ja personaalne tugi. 


\section{Kaasava hariduse võtmetunnused alushariduses}

Võtmetunnustena käsitletakse neid aspekte ja tegevusi, mis on kirjanduses välja toodud kvaliteetse kaasava hariduse rakendamisel haridussüsteemi eri tasanditel alushariduse eripärast lähtuvalt. Kirjanduse ülevaate kohaselt on alushariduses kaasava hariduse edukaks rakendamiseks vajalik arvestada 43 tunnusega. See on raskesti hoomatav hulk tunnuseid ja seetõttu tuleb luua süsteem, mis võimaldab nendega kaasava hariduse rakendamisel arvestada. Analüüsi põhjal pakume välja 14 võtmetunnuste alakategooriat ja viis peakategooriat ehk dimensiooni: laps, õpetaja, perekond, organisatsioon ja riik. Leitud dimensioonid võib välja tuua tasanditena, mille keskmes on subjekt, kes on seotud tasandi võtmetunnustega (vt http://sisu.ut.ee/kaasavharidus/).

\section{Laps}

Lapse tasandil tuvastati kümme võtmetunnust, mida võiks kirjeldada neljas kategoorias: lapse omadused, füüsiline, sotsiaalne ja psüühiline kaasatus (vt http://sisu.ut.ee/kaasavharidus/).

Lapse omadused hõlmavad kahte erinevat aspekti: lapse isikuomadused ning tema eripära, sealhulgas lapse käitumisraskused ja erivajaduse tunnused. Erivajaduse tunnuste osas saab omakorda välja tuua erivajaduse liigi (nt kuulmispuue, nägemiskahjustus, Downi sündroom, autism) ja erivajaduse raskusastme või sügavuse.

Füüsiline kaasatus hõlmab keskkonna korraldamist, õpetajate ja laste suhtarvu ning laste osalemist kaasavas rühmaruumis. Kirjanduse põhjal on keskkonna korraldamine seotud ruumi, sisustuse ja õppematerjalidega ning tähendab nende kohandamist ja seda, kuidas lapsed ruumi ja vahenditega suhestuvad. Õpetajate ja laste suhtarvu nähakse kaasamise edukuse olulise eeldusena ja tuuakse välja kaks aspekti: personali ja laste suhtarv ning erivajadustega laste ja tavapärase arenguga laste suhtarv, mis mõlemad võiksid olla väiksemad, kui on seni tavarühmas olnud.

Sotsiaalne kaasatus hõlmab allikate põhjal sotsiaalset aktiivsust, mida näitavad laste omavahelised suhted ja sõprus. Sotsiaalse kaasatuse peamine roll on hõlbustada eakaaslastega positiivsete suhete ja sõprussuhete loomist. Sotsiaalse läbikäimise tulemusel paranevad laste sotsiaalsed oskused, suhtlemisoskus ja konfliktide lahendamise oskus. Analüüsi tulemustest selgus, et sotsiaalne kaasatus mõjutab laste üldist suhtumist erivajadustega lastesse ja aitab paremini mõista erivajadustega laste olukorda (Kwon et al., 2017).

Psüühiline kaasatus tähendab kuuluvustunnet ja liikmelisust, laste tervise hoidmist ja turvalisust, iga lapse aktsepteerimist ja emotsionaalset tuge. Kõikidel lastel on võrdne võimalus osaleda alushariduses koos tavapäraselt 
arenenud eakaaslastega ning tunda end selle rühma võrdväärse liikmena. See tähendab, et koolieelne lasteasutus ja kogukond aktsepteerivad kõigi laste ja nende perede valikuid lasteasutuses osalemiseks ja loovad tingimused, mis tagavad lapse heaolu ja toetavad kuuluvustunde tekkimist. Näiteks võiks erinevuste väärtustamine olla üks lasteasutuse põhiväärtustest ja nii täiskasvanute suhtumine kui ka tegevus peaks soodustama erivajadustega laste ja nende perede kaasamist.

\section{Õpetaja}

Õpetaja tasandil tuvastati kümme võtmetunnust, mida kirjeldatakse kahes kategoorias: õpetaja omadused ja õpetamine (vt http://sisu.ut.ee/kaasavharidus/).

Õpetaja omadused hõlmavad õpetajate isikuomadusi, mis on vajalikud väikeste lastega töötamisel ning õpetaja esmaõppes ja täienduskoolituses omandatud pädevusi ja kvalifikatsiooni. Õpetaja pädevused kaasava hariduse kohta annavad õpetajale kindlustunde ja hõlmavad nii teadmisi (sh praktilisi teadmisi, nt erivajadusega lapse toetamine, õpivara kohandamine, mis kujunevad õpetamispraktika käigus) ja oskusi kaasava hariduse kohta kui ka väärtusi ja hoiakuid. Viimaste hulka kuuluvad üldised uskumused, enesetõhusus, kaasamise valmidus ja pühendumine, mis kõik loovad eelduse edukaks tegutsemiseks kaasavas õpikeskkonnas.

Õpetamine peab tagama õppeprotsessi kvaliteedi. Kvaliteetne õppeprotsess sisaldab varajast märkamist, sobivate eesmärkide seadmist, kaasavat õppetegevust, sealhulgas sobivaid vahendeid, ópivara ja tehnoloogia kasutamist, positiivseid suhteid ja õpetajate refleksiooni oma õpetamise üle. Õpetamine kaasavas rühmaruumis tähendab lapse eripära arvestamist ja individuaalset lähenemist koos spetsiifiliste sekkumiste, toetava suhtluse, juhendamise, diferentseeritud tegevuste ja kõrgete ootustega kõigile lastele, mis aitavad rakendada iga lapse potentsiaali. Õpetamine tugineb laste huvile ja võimaldab õppimist isiklikust kogemusest, kus lapsel on võimalik teha ise valikuid nii õppevahendite ja -materjalide kui ka lahendusteede üle. Laps on kogu õppeprotsessi aktiivselt kaasatud ja õpetaja roll seisneb pidevas tagasisidestamises, juhendamises ja vajaduse korral sekkumises. Analüüsitud allikate põhjal mõjutavad positiivset mikrokliimat laste ja täiskasvanute interaktsioon õppeja kasvatustegevuses, täiskasvanute kaasatus laste omavahelisse suhtlemisse ning täiskasvanute ja laste üldised suhted rühmas. Hindamine ja tagasiside seisneb laste õppimise ja arengu jälgimises ja peaks toetama kõigi laste, sealhulgas erivajadustega laste tulemuslikku osalemist õppe- ja kasvatustegevuses, lapse arengut ja edasiminekut õppekava mõttes. See ei tohiks olla pelgalt lapse 
arengu tabelite täitmine, vaid peaks sisaldama süsteemset lähenemist: sobivate hindamismeetodite kasutamist, tulemuste dokumenteerimist ja analüüsi, läbimõeldud esitamist ja interpreteerimist. Näiteks võiks mõelda tulemuste selgemaks esitamiseks nende visuaalsele esitamisele diagrammide ja jooniste kujul, kus on näha olulised aspektid laste arengus, mille põhjal kavandada edasine õpi- ja õpetamistegevus. Samuti toodi analüüsitud kirjanduses välja reflekteerimine oma õpetamise üle eesmärgiga hinnata ja analüüsida õpetamise meetodeid. Refleksioon aitab välja selgitada õpetaja professionaalse arengu vajadused. Refleksiooni mudelite kasutamine aitab tõsta refleksiooni kvaliteeti.

\section{Perekond}

Perekonna tasandil tuvastati analüüsi tulemusel kuus võtmetunnust, mida võib kirjeldada kahes kategoorias: perekonna kaasamine ja perekonna toetamine (vt http://sisu.ut.ee/kaasavharidus/).

Perekonna kaasamine tähendab sisukat partnerlust lasteasutuse ja pere vahel, mis arvestab pere võimalusi ning pere vajaduste ja ootuste ning lasteasutuse võimaluste omavahelist sobitumist. Sisuka partnerluse puhul on vaja kodu ja lasteasutuse vahelist suhtlust, milleks on valitud sobivad viisid, nagu personaalsed vestlused, elektrooniline suhtlus ning vanemate rühmaruumi külastused ja õpetajate kodukülastused. Perekonna kaasamine hõlmab ka info kättesaadavust ja seetõttu on oluline, et info edastamiseks kasutatakse erinevaid viise. Kaasamist mõjutavad veel vanemaid iseloomustavad omadused ja pere arusaam kaasavast haridusest. Seetõttu võiks koostöö alguse saada lähemast tutvumisest perega, et ühtlustada arusaam ja ootused.

Perekonna toetamine tähendab vanemate koolitamist ja individuaalset teenuste kava perele. Vanemate koolitamine toetab vanemaid lapse arendamisel ja on seotud teemadega, mis vanemaid kõnetavad. Tulenevalt perede eripäradest võimaldatakse neile vajalikud teenused, mis on lasteasutuses kättesaadavad - näiteks eripedagoogi, logopeedi või psühholoogi tugi.

\section{Institutsioon}

Institutsiooni tasandil tuvastati seitse võtmetunnust, mida võiks kirjeldada kahes kategoorias: organisatsiooni kultuur ja organisatsiooni struktuursed omadused (vt http://sisu.ut.ee/kaasavharidus/).

Organisatsioonikultuur hõlmab sotsiaal-kultuurilisi väärtusi ja uskumusi, kaasamise filosoofiat ja kaasamise mõiste tõlgendamist ning infrastruktuuri tuge. Lisaks täpselt määratletud õppekava sisu ja paindlikku õppekava järgimist, mis arvestab õppijate vajaduste ja võimetega. Asutuse kultuur sisaldab ka personali toetamist nende püüdlustes saada pädevateks, enesekindlateks 
spetsialistideks. See tähendab koostööle orienteeritud kultuuri: professionaalset koostööd, meeskonnana tegutsemist, kollegiaalset tuge, suhtlemist, mentorlust, juhendamist ja juhendeid ning head info liikumist.

Organisatsiooni struktuursed omadused tähendavad organisatsiooni süsteemi ümberkorraldamist, et võimaldada ressursse ja tugiteenuseid kõigile lastele ja õpetajatele. Struktuursed omadused hõlmavad eestvedamist ja juhtimist, haldusküsimusi, ametialaseid otsuseid ja kooli võimalusi personalitöös. Personalitöö tähendab õpetajate töökoormust, lisapersonali, palku ja hüvitisi, puhkeaega ja aja planeerimist peredega koostöö tegemiseks ning eeldab kaasamisele pühendumist. Eestvedamine ja juhtimine ning kõik juhtimisotsused peaksid kõike seda toetama. Odom jt (1999) toovad välja, et struktuursed omadused esinevad erinevates organisatsioonilistes kontekstides ja kaasamiseks võib olla erinevaid vorme. Hanson jt (2001, lk 71) toovad aga esile, et kaasamine alushariduses võib toimuda mitmel tasandil sõltuvalt erivajadustega laste kaasamise määrast ühistegevustesse tavapäraselt arenenud lastega. Nad toovad välja neli kaasamise võimalust. Kõikehõlmav ja täielik kaasamine tähendab, et erivajadustega lapsed osalevad tavarühmas koos tavapäraselt arenenud eakaaslastega kogu lasteasutuses viibitud aja jooksul. Modifitseeritud, tervikliku ja täieliku kaasamise korral osalevad erivajadusega lapsed poole ajast tavarühma tegevustes koos tavapäraselt arenenud eakaaslastega ja ülejäänud päeva spetsiaalselt neile mõeldud tegevustes koos teiste erivajadustega lastega. Terviklikul ja osalisel kaasamisel osalevad erivajadustega lapsed enamasti omaette tegevustes ja aeg-ajalt ühistes tegevustes koos tavapäraselt arenenud lastega. Spetsiifilise ja eraldatud õppe korral on tegemist erivajadustega laste eraldatud õpetamisega, kus neid õpetatakse eraldi ruumis ja teiste lastega puutuvad nad kokku vaid ühiskasutatavates ruumides.

\section{Riik}

Riigi tasandi võtmetunnuseid tuvastati kümme ja need esitatakse neljas kategoorias: poliitika ja seadustik, koostöö, ressursid ning monitooring ja hindamine (vt http://sisu.ut.ee/kaasavharidus/).

Poliitika ja seadustik tähendavad kohaliku konteksti arvestamist ning seaduste ja määruste loomist, sealhulgas õppekava ja riiklikku kaasamise poliitikat. Kirjanduses peetakse oluliseks kaasamise filosoofiat ehk kaasava hariduspoliitika tõlgendamist riigis. See eeldab olulist nihet hariduspoliitikas koostööl põhineva koolikultuuri rajamise suunas, tulemuslike pedagoogikate sõnastamist ehk õpikäsitust, kus on esiplaanil sotsiaalse õigluse ja võrdsuse küsimused. See eeldab sotsiaal-kultuurilisi väärtusi ja veendumusi ning kohaliku kultuuri, kultuurilise ja keelelise mitmekesisuse ning demograafilise seisu arvestamist. 
Koostöö hõlmab riigiasutuste tuge ja asutustevahelist koostööd. See tähendab suhteid alushariduse valdkonna sektoriga, koostööd lasteaiaõpetajate, eripedagoogide ja teiste spetsialistide vahel, kogukonna osalust ja kogukonna mõjutamist.

Ressursid hõlmavad rahalist tuge, sobivat infrastruktuuri ja materiaalset baasi. Seejuures tuleks üle vaadata senised võimalused ja mõelda, kuidas need toetavad kaasava hariduse rakendamist.

Monitooring ja hindamine on kirjanduse põhjal vajalik kaasava hariduse kvaliteedi tagamiseks. Pidev monitooring ja hindamine, mis sisaldavad ka kõigi kaasavas hariduses osalejate arvamusi, toetab kvaliteetse kaasamise rakendamist (Salisbury, 1990).

\section{Arutelu ja järeldused}

Süstemaatilise kirjandusanalüüsi põhjal esitati artiklis kaasava hariduse definitsioon ja võtmetunnused alushariduse kontekstis. Kirjanduses tõstetakse kaasava hariduse mõistest rääkides esile selle filosoofilist olemust. Tegemist on mõtteviisiga ja arutletakse selle üle, miks kaasamine on väärtuslik ja kasulik nii erivajadustega kui ka erivajadusteta lastele. See on oluline nihe hariduspoliitikas, kus erivajadustega laste eraldatuse asemel liigutakse mitmekesisuse väärtustamise poole kaasavas õpikeskkonnas (Lundqvist et al., 2015; Zang, 2011). Eestis on olnud haridussüsteem, kus erivajadustega laste eraldamine erilasteaedadesse või erirühmadesse on olnud tavapärane. Seetõttu on arusaadavalt selline nihe hariduspoliitikas väljakutseks nii õpetaja, institutsiooni kui ka riigi tasandil. Õpetajad peavad olema valmis mõistma laste mitmekesisust ning omandama teadmised ja oskused õpikeskkonna ja tegevuste kohandamiseks, sest igal erivajadusega lapsel ja tema perekonnal on õigus ja vaba valik osaleda lasteasutuse ja kogukonna tegevustes. Riigi ja institutsiooni tasandil tähendab see tahet ja soovi vastu võtta otsused ja kujundada lähenemine, mis võimaldab õpetajatel tagada igale lapsele võrdne juurdepääs haridusele. Eestis on suurel osal lastest haridusele juurdepääs varasemas eas kui teistes riikides. 2016. aastal osales alushariduses ja lastehoidudes 71\% kaheaastastest lastest, OECD keskmine oli $45 \%$ ja EL keskmine $42 \%$. Kolmeaastaste alushariduses osalevate laste arv kasvab Eestis 90\%ni, OECD keskmine on 76\% ja EL keskmine 82\% (OECD, 2018b). Võimalus osaleda tavapäraselt arenenud lastega samas keskkonnas aitab suurendada kuuluvustunnet ja tunnet, et ollakse teiste poolt väärtustatud ja aktsepteeritud. 
Kaasamise praktiline olemus tähendab, et erivajadustega lapsed kaasatakse tavarühmadesse, kuid sageli puudub arutelu selle üle, mida see tähendab lastele või ka õpetajatele, kes peavad mitmekesistama oma õpetamisprotsessi, et seda kohandada iga lapse vajadustele. Kaasava hariduse praktilise olemuse keskmes on kaasamise võimaldamiseks vajalikud praktilised küsimused, näiteks tugiteenused ja protsessid riigi ja organisatsiooni tasandil (Love, 2018), tagamaks, et kõiki lapsi, sealhulgas erivajadustega lapsi, õpetaks nende enda rühmaõpetaja ühes ja samas rühmaruumis (Hoskin et al., 2015). Kaasava hariduse põhimõtted peavad kajastuma ja olema kättesaadavad poliitikates, õppekavades, infrastruktuuris ja õpetamisel. Koolieelse lasteasutuse riiklikus õppekavas (2008) kirjeldatud õpikäsitus sätestab, et mängudes ning õppe- ja kasvatustegevuses arvestatakse laste eripära ning õpetajad on lapse arengu suunajad ja toetava keskkonna loojad. Siiski ei kajastu kaasava hariduse olemus ja põhimõtted kehtivas riiklikus õppekavas piisaval määral ning õppekava vajab muutmist kaasava hariduse määratluse kohaselt. Lisaks on kirjanduse põhjal oluline haridusstrateegias ja õppekavas esitatud põhimõtete ja lähenemisviisi arutelu ühiskonnas kaasava hariduse eesmärkide realiseerimiseks. Jagatud arusaam kaasavast haridusest mõjutab selle rakendamist (Florian, 2017; Stone, 2014; Sukumaran et al., 2015). Varasemate Eestis tehtud uuringute tulemused on näidanud, et kaasava hariduse tähendust tõlgendatakse spetsialistide, õpetajate ja haridusjuhtide seas erinevalt (Häidkind \& Oras, 2016; Kivirand et al., 2020).

Teiseks analüüsiti kaasava hariduse võtmetunnuseid ja leiti, et artiklites mainitud tunnuseid saab esitada viiel tasandil: lapse, pere, õpetaja, asutuse ja riigi tasandil. See sarnaneb Bronfenbrenneri ja tema kolleegide välja töötatud bioökoloogilise mudeliga (Love, 2018; Næsby, 2018; Sukumaran et al., 2015). Erinevalt sellest mudelist otsustati praeguses mudelis tekitada tasandid kaasava hariduse rakendamise võtmetunnustega seotud subjekti põhjal, sest süstemaatilise kirjandusanalüüsi põhjal on ka kaasava hariduse definitsiooni keskmes subjektina laps.

Siinses uuringus leiti, et kaasava hariduse võtmetunnuseid saab süstematiseerida viie tasandi kaudu, ja loodi nende kirjeldamiseks mudel. Mudeli keskmes on kaasava hariduse definitsioon. Kusjuures kaasava hariduse edukaks rakendamiseks tuleb tõlgendada definitsiooni alushariduse kontekstis. Mudeli iga taseme keskmeks on subjekt, kes on seotud võtmetunnustega, vastutab nende kättesaadavuse ja kvaliteedi eest ehk mõjutab võtmetunnuseid sellel tasandil või on ise mõjutatud nendest tunnustest. Mudel viitab ka sellele, kuidas on tasemed omavahel seotud (vt joonist 2). 


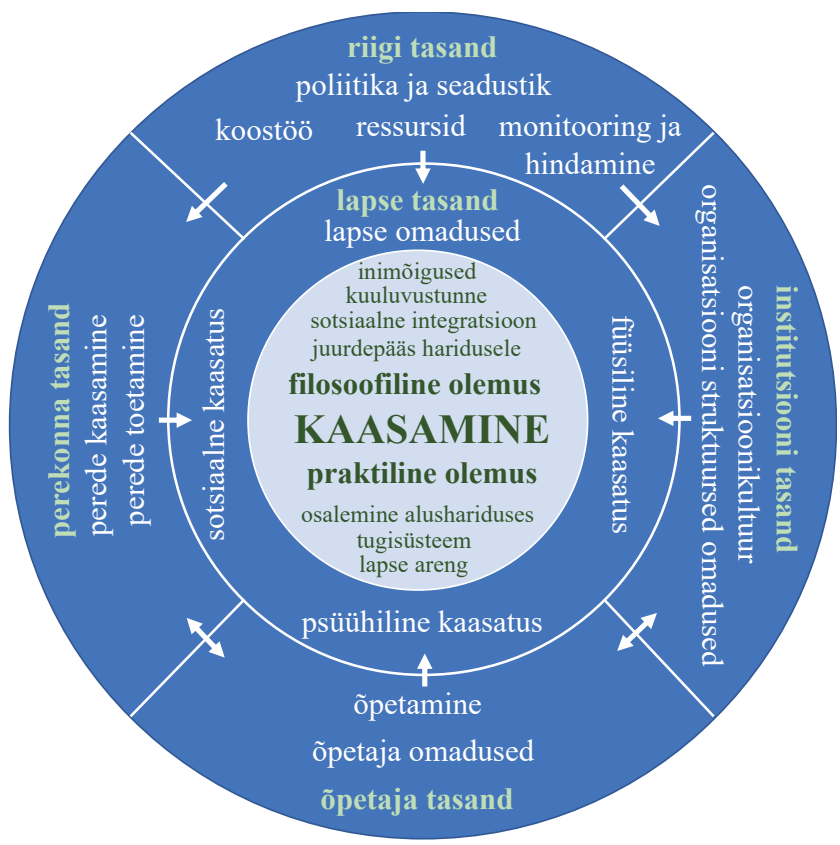

Joonis 2. Mudel kaasava hariduse rakendamiseks.

Lapse tasandit mõjutavad kõik teised tasandid sinisel välimisel ringil, kuid enamasti õpetajate, perekonna ja asutuse tasandid ning kaudselt ka riigi tasand. Lapse tasandi võtmetunnused nagu lapse omadused, füüsiline, sotsiaalne ja psüühiline kaasatus on need, millega tuleb teistel tasanditel arvestada. Samuti tuleb arvestada õpetajate ja laste suhtarvuga, mis OECD (2018b) raporti kohaselt on Eestis kolme- kuni viieaastaste laste rühmades 12 last täiskasvanu kohta. Alla kümne lapse õpetaja kohta on raporti kohaselt vaid viies riigis, sealhulgas Soomes ja Norras. Norras on kaheaastaste laste rühmas õpetaja ja laste suhtarv koguni kolm last ühe täiskasvanu kohta, samal ajal kui Eestis on see kaheksa. Kirjanduse põhjal on kaasava hariduse edukal rakendamisel oluline pigem väiksem laste arv õpetaja kohta, kui on seni tavarühmas olnud (Næsby, 2018; Pelatti et al., 2016).

Õpetaja tasandi võtmetunnused mõjutavad nii lapse tasandi kui ka perekonna ja institutsiooni tasandi võtmetunnuseid. Lapse, perekonna, institutsiooni ja nende kaudu ka riigi tasandi võtmetunnused mõjutavad omakorda õpetaja tasandi võtmetunnuseid. Õpetamise kvaliteedi oluliseks eelduseks on õpetajate omadused, näiteks õpetaja esmaõppes ja täienduskoolituse käigus omandatud pädevused (Hewett, 1999; Soukakou et al., 2018), tema hoiakud ja uskumused (Hoskin et al., 2015; Park, Dimitrov, \& Park, 2018). Õpetaja teadmistest ja hoiakutest sõltub see, kuidas õpetaja tuleb toime õpetamisega 
kaasavas keskkonnas (Park et al., 2018). Õpetajad, kellel on positiivne hoiak kaasava praktika suhtes, kasutavad iseenesestmõistetavamalt ja loomulikult kaasavaid õpetamisstrateegiaid (Sucuoğlu, Bakkaloğlu, Işcen Karasu, Demir, \& Akalin, 2013). Häidkind ja Oras (2016) toovad oma uuringus välja, et Eestis on lasteaiaõpetajate hoiakud kaasamise suhtes positiivsemad kui koolis. See võib olla tingitud sellest, et lasteaias viibivad logopeed ja eripedagoog sagedamini rühmas ja toetavad õpetajaid nende igapäevases tegevuses, jagades konkreetseid näpunäiteid erivajadustega laste kaasamisel.

Erivajadustega laste kaasamisel kogevad õpetajad raskusi seoses laste käitumise ja õppimise probleemidega ning õppekorraldusega (Häidkind \& Oras, 2016). Seega tuleb lasteaiaõpetajate ettevalmistuses ja jätkuõppes pakkuda võimalusi õpetajate kompetentsi tõstmiseks erivajadusega laste kaasamisel. Poom-Valickis ja Ulla (2020) toovad välja, et sobivaks õppevormiks kaasava hariduse hoiakute tõhustamisel võib pidada teoreetiliste teadmiste integreerimist praktilise ja reflekteeriva õppevormiga. Reflekteerimine oma õpetamise üle aitab välja selgitada ka professionaalse enesearengu vajaduse ning parandab õpetajate õpetamispädevust. Lasteaiaõpetaja pädevused, sealhulgas pädevused erivajadustega laste kaasamiseks, on kirjeldatud kutsestandardis „Õpetaja, tase 6“ (2019). Kutsestandard aitab õpetajal orienteeruda vajalikes pädevustes ja eneserefleksiooni abil leida vajadus enesetäiendamise järele (Pedaste, Leijen, Poom-Valickis, \& Eisenschmidt, 2019).

Perekonna tasandi võtmetunnused, nagu pere kaasamine ja perede toetamine, on kaasava hariduse rakendamisel hädavajalikud (Frankel, Gold, \& Ajodhia-Andrews, 2011; Zhang, 2011) ja mõjutavad mudeli järgi õpetaja, asutuse ja riigi tasandit ning need, nagu eespool öeldud, mõjutavad omakorda lapse, õpetaja ja asutuse tasandit. Perekonna ja lasteasutuse koostöö, kus aktiivselt suheldakse ja infot vahetatakse, tagab lasteaia tegevuste vastavuse pere ootustele ja vajadustele. Eesti lasteaedades nõustavad lapsevanemaid õppe- ja kasvatusküsimustes lasteaiaõpetajad (Koolieelse lasteasutuse seadus, 1999). Lapse kõne arengu toetamisel nõustab peret logopeed ning erivajadustega toimetulemisel eripedagoog või hariduslike erivajaduste koordinaator. Samas on Eestis suur puudus nii logopeedidest kui ka eripedagoogidest. OSKA (2018) raporti kohaselt vajab aastatel 2018-2025 Eesti haridussüsteem juurde umbes 330 eripedagoogi ja vähemalt 120 logopeedi. Seega seisab ka Eesti alusharidus silmitsi suure katsumusega tugispetsialistide vajaduse katmisel.

Institutsiooni tasandi võtmetunnuseid mõjutavad õpetaja, pere ja riigi tasandi võtmetunnused ning asutuse tasandi võtmetunnused mõjutavad organisatsioonikultuuri ja struktuursete omaduste kaudu omakorda lapse, õpetaja ja pere tasandit. Cologoni (2014) järgi on kaasamine organisatsiooni kultuuri küsimus ja iga asutus loob ise oma kultuuri, kuid ka teised tasandid, mis 
mudelis on esitatud, annavad sellele oma panuse. Koolieelsed lasteasutused peavad kujundama oma kaasamise filosoofia, mis lähtub sotsiaal-kultuurilise käsitluse aspektidest ja sellest tulenevatest väärtustest.

Arcidiacono ja Baucal (2020) toovad Võgotskile tuginedes välja, et sotsiaal-kultuurilise lähenemise seisukohalt peegeldab lapse erivajadus keskkonna eripära ning selle võimetust tagada lapsele sobivaid tingimusi sotsiaalkultuurilises tegevuses osalemiseks, mitte aga lapse enda individuaalset eripära. Seega langeb vastutus eeskätt institutsioonile, et luua sobiv keskkond kaasamiseks koos tavapäraselt arenenud lastega, mitte taandada raskused kaasamisel lapse erivajadusele ja sellest tulenevalt lahendada olukord lapse paigutamisel erirühma või erilasteaeda. Samas vajavad tuge ka õpetajad, sest sotsiaal-kultuurilise käsitluse kohaselt sõltub pädevaks kaasavat lähenemist rakendavaks õpetajaks kujunemine paljudest sotsiaalsetest, kultuurilistest ja institutsionaalsetest komponentidest, mitte ainult õpetajate individuaalsetest omadustest (Arcidiacono \& Baucal, 2020). Seetõttu tuleb kujundada toetav ja koostööle orienteeritud organisatsioonikultuur, kus õpetajatele pakutakse mitmekülgset tuge, et nad saaksid oma pädevusi arendada.

Peale organisatsioonikultuuri on tähtsad institutsiooni struktuursed omadused, nagu eestvedamine ja juhtimine, haldusküsimused ja ametialased otsused, samuti personaliga seotud ressursid (nt töökoormus, lisapersonal, töötasud ja hüvitised, puhkeaeg), mis peavad olema piisavad ja tagama kaasamise eduka rakendamise. See sõltub sageli juhtimisotsustest, mis omakorda sõltub suuresti juhtide hoiakutest kaasavasse haridusse, mida seni Eestis veel piisavalt uuritud ei ole. Samuti ei ole piisavalt suurt tähelepanu pööratud juhtide koolitamisele kaasava hariduse vallas.

Riigi tasand mõjutab kõiki teisi tasandeid kohalike seaduste ja riikliku kaasamise poliitika, koostöö, ressursside ning monitooringu ja hindamise kaudu. Kaasav hariduspoliitika ja selle mõistmine riigis on üks peamisi tunnuseid, mis tagab kaasava hariduse eduka rakendamise (Sukumaran et al., 2015). Kehtivas koolieelse lasteasutuse seaduses (1999) ei ole kaasava hariduse põhimõtetele kuigi palju tähelepanu pööratud. Samas on koostatud lapsehoiu ja alushariduse kontseptsioon ja eesmärk on vastu võtta uus alushariduse seadus ja muuta lapse alushariduse korralduse süsteem sidusamaks ja paindlikumaks (Haridus- ja Teadusministeerium, 2019). Samuti on kvaliteetse kaasava hariduse rakendamiseks vaja piisavalt rahalist tuge ja ressursse riigilt, mis on olnud Eesti alushariduse üks peamisi kitsaskohti kaasava hariduse rakendamisel. Kõige rohkem avaldab ressursside suurendamisele survet soovitus vaadata üle laste ja õpetajate suhtarv kaasava hariduse rakendamise korral, samuti tugispetsialistide värbamine ja sobiva õpikeskkonna kujundamine. Samas aitab ülevaadet ressursside vajaduse kohta välja selgitada pidev monitooring, mis 
peaks tagama kaasava hariduse kvaliteedi ja sisaldama ka kaasavas hariduses osalejate tagasisidet (Odom et al., 2011; Salisbury, 1990). Eestis rakendatakse sisehindamist, mis aitab lasteasutusel hinnata oma tegevuse tulemuslikkust ja kavandada arendustegevusi, kuid annab ka riigile tagasisidet vajalike indikaatorite kohta ning sisendi kvaliteetse kaasava hariduse rakendamise tõhustamiseks ja ressursside suunamiseks.

Siinses töös välja arendatud mudel esitab kvaliteetse kaasava hariduse rakendamiseks vajaliku definitsiooni ja võtmetunnused tasandite kaupa. Definitsiooni mõlemad aspektid, filosoofiline ja praktiline olemus, peaksid olema hästi mõistetud ja interpreteeritud. Kaasava hariduse eduka rakendamise kindlustamiseks tuleks arvestada iga tasandi võtmetunnustega. Mudeli tasandite loomisel subjektist lähtumine aitab kindlaks teha, kes vastutab võtmetunnuste kvaliteedi või kättesaadavuse eest igal tasandil, mis on oluline ja vajalik kaasava hariduse rakendamisel. Need tulemused on väärtuslikud õpetajakoolituse õppekavade koostamisel, et parandada alushariduse õpetajate oskusi kaasava hariduse rakendamiseks. Mudel aitab kaasa ka õpetajate professionaalse arengu vajaduste selgitamisele ja kaasava hariduse rakendamisele üldiselt. Samuti saab koostatud raamistikule tuginedes tegeleda edasi kaasava hariduse seisu või õpetajate kompetentsi hindamise vahendite väljatöötamisega, et seejärel kavandada ka raamistiku põhjal tegevusi, kuidas liikuda senisest enam kaasava hariduse suunas.

\section{Tänusõnad}

Artikli valmimist toetas EMP ja Norra finantsvahendite eeldefineeritud projekt „Kaasava hariduse õppekava arendamine ja õpetamise kvaliteedi tõhustamine“, lepingu $\mathrm{nr}$ 36.1-3.4/289.

\section{Kasutatud kirjandus}

Alexander, P. A. (2020). Methodological Guidance Paper: The Art and Science of Quality Systematic Reviews. Review of Educational Research, 90(1), 6-23. https://doi.org/10.3102/0034654319854352

Arcidiacono, F., \& Baucal, A. (2020). Kaasav haridus ja õpetajakoolitus sotsiaal-kultuurilisest käsitlusest lähtudes. Eesti Haridusteaduste Ajakiri, 8(1), 5-25 https://doi.org/10.12697/eha.2020.8.1.02a

Bossaert, G., Colpin, H., Pijl, S. J., \& Petry, K. (2013). Truly included? A literature study focusing on the social dimension of inclusion in education. International Journal of Inclusive Education, 17(1), 60-79, https://doi.org/10.1080/13603116.2011.580464 
Botha, J., \& Kourkoutas, E. (2016). A community of practice as an inclusive model to support children with social, emotional and behavioural difficulties in school contexts. International Journal of Inclusive Education, 20(7), 784-799, https://doi.org/10.1080/13603116.2015.1111448

Capp, M. J. (2017). The effectiveness of Universal Design for Learning: A meta-analysis of literature between 2013 and 2016. International Journal of Inclusive Education, 21(8), 791-807. https://doi.org/10.1080/13603116.2017.1325074

Chhabra, S., Bose, K., \& Chadha, N. (2018). Early Childhood Educators' Perspectives and Practices About Inclusion of Children with Special Needs in Botswana. Journal of Research in Childhood Education, 32(2), 234-249. https://doi.org/10.1080/02568543.2018.1425223

Cologon, K. (2014). Preventing Inclusion? Inclusive Early Childhood Education and the Option to Exclude. Contemporary Issues in Early Childhood, 15(4), 378-381. https://doi.org/10.2304/ciec.2014.15.4.378

De Jager, T. (2013). Guidelines to assist the implementation of differentiated learning activities in South African secondary schools. International Journal of Inclusive Education, 17(1), 80-94. https://doi.org/10.1080/13603116.2011.580465

European Agency for Special Needs and Inclusive Education, (2017). In F. Bellour, P. Bartolo, \& M. Kyriazopoulou (Eds.), Inclusive early childhood education. Literature Review. Denmark: Odense.

European Commission, 2014. Proposal for key principles of a Quality Framework for Early Childhood Education and Care. Report of the Working Group on Early Childhood Education and Care under the auspices of the European Commission. European Commission B-1049 Brussels.

Frankel, E. B., Gold, S., \& Ajodhia-Andrews, A. (2010). International Preschool Inclusion: Bridging the Gap Between Vision and Practices. Young exceptional children, 13(5), 2-16. https://doi.org/10.1177/1096250610379983

Fyssa, A., Vlachou, A., \& Avramidis, E. (2014). Early childhood teachers' understanding of inclusive education and associated practices: reflections from Greece. International Journal of Early Years Education, 22(2), 223-237. https://doi.org/10.1080/09669760.2014.909309

Gaffney M., \& Wilkins, J. (2016). Selecting picture books featuring characters with autism spectrum disorder: recommendations for teachers. International Journal of Inclusive Education, 20(10), 1024-1031. https://doi.org/10.1080/13603116.2016.1145262

Haridus- ja Teadusministeerium (2019). Haridus- ja Teadusministeeriumi 2018. aasta tulemusaruanne. Tartu: HTM. https://www.hm.ee/et/tegevused/uuringud-ja-statistika-0

Harrison, J. R., Soares, D. A., \& Joyce, J. (2019). Inclusion of students with emotional and behavioural disorders in general education settings: a scoping review of research in the US. International Journal of Inclusive Education, 23(12), 12091231. https://doi.org/10.1080/13603116.2018.1444107

Haug, P. (2017). Understanding Inclusive Education: Ideals and Reality. Scandinavian Journal of Disability Research, 19, 206-217. https://doi.org/10.1080/15017419.2016.1224778 
Hewett, V. M. (1999). A Case Study of An Inclusive Early Childhood Setting. Early Education and Development, 10(4), 535-549. https://doi.org/10.1207/s15566935eed1004_7

Hoskin, J., Boyle, C., \& Anderson, J. (2015). Inclusive education in pre-schools: predictors of pre-service teacher attitudes in Australia. Teachers and Teaching, 21(8), 974-989. https://doi.org/10.1080/13540602.2015.1005867

Hu, B. Y., Roberts, S. K.,Wang, Y., \& Zhao, H. (2011). The initiation of early childhood inclusion in China: a case study from Beijing. International Journal of Early Years Education, 19(2), 111-131. https://doi.org/10.1080/09669760.2011.596396

Häidkind, P., \& Oras, K. (2016). Kaasava hariduse mõiste ning õpetaja ees seisvad ülesanded lasteaedades ja esimeses kooliastmes. Eesti Haridusteaduste Ajakiri, 4(2), 60-88. https://doi.org/10.12697/eha.2016.4.2.04

Kivirand, T., Leijen, Ä., Lepp, L., \& Malva, L. (2020). Kaasava hariduse tähendus ja tõhusa rakendamise tegurid Eesti kontekstis: õpetajaid koolitavate või nõustavate spetsialistide vaade. Eesti Haridusteaduste Ajakiri, 8(1), 48-71.

https://doi.org/10.12697/eha.2020.8.1.03

Koolieelse lasteasutuse seadus. (1999). Riigi Teataja I, 1999, 27, 387. Külastatud aadressil: https://www.riigiteataja.ee/akt/114032011006

Koolieelse lasteasutuse riiklik õppekava. (2008). Riigi Teataja I, 2008, 23, 152. Külastatud aadressil: https://www.riigiteataja.ee/akt/12970917

Kutsestandard. Oppetaja, tase 6. (2019). Hariduse kutsenõukogu. Külastatud aadressil: https://www.kutseregister.ee/ctrl/et/Standardid/vaata/10746581

Kwon, K.-A., Hong, S.-Y., \& Jeon, H.-J. (2017). Classroom Readiness for Successful Inclusion: Teacher Factors and Preschool Children's Experience with and Attitudes Toward Peers with Disabilities. Journal of Research in Childhood Education, 31(3), 360-378. https://doi.org/10.1080/02568543.2017.1309480

Lawrence, S., Smith, S., \& Banerjee, R. (2016). Preschool Inclusion. Key Findings from Research and Implications for Policy. Külastatud aadressil: https://eric.ed.gov/contentdelivery/servlet/ERICServlet?accno=ED579178

Loreman, T. (2014). Measuring inclusive education outcomes in Alberta, Canada. International Journal of Inclusive Education, 18(5), 459-483, https://doi.org/10.1080/13603116.2013.788223

Love, H. R. (2018). Understanding High-Quality Inclusive Education Across Early Childhood Settings. Dissertation. University of Kansas.

Lundqvist, J., Mara, A. W., \& Siljehag, E. (2015). Inclusive education, support provisions and early childhood educational pathways in the context of Sweden: a longitudinal study. International journal of special education, 30(3), 3-16.

Mayring, P. (2014). Qualitative content analysis. Theoretical foundation, basic procedures and software solution. Külastatud aadressil: https://nbn-resolving.org/urn:nbn:de:0168-ssoar-395173

Mets, U., \& Viia, A. (2018). Tulevikuvaade tööjõu- ja oskuste vajadusele: haridus ja teadus. Uuringu lühiaruanne. Tallinn: SA Kutsekoda.

National Early Childhood Technical Assistance Center, (2011). Evaluation summary of the Expanding Opportunities Interagency Inclusion Initiative. Külastatud aadressil: http://www.nectac.org/ pdfs/pubs/exp_opps_eval_summary.pdf 
Næsby, T. (2018). The quality of inclusion in Danish preschools. Early Child Development and Care. https://doi.org/10.1080/03004430.2018.1541320

Odom, S. L., Horn, E. M., Marquart, J. M., Hanson, M. J., Wolfberg, P., Beckman, P., Lieber, J., Li, S., Schwartz, I., Janko, S., \& Sandall, S. (1999). On the Forms of Inclusion: Organizational Context and Individualized Service Models. Journal of Early Intervention, 22(3), 185-199. https://doi.org/10.1177/105381519902200301

Odom, S. L. (2002). Narrowing the question: social integration and characteristics of children with disabilities in inclusion settings. Early Childhood Research Quarterly 17, 167-170. https://doi.org/10.1016/S0885-2006(02)00150-3

Odom, S. L., Buysse, V., \& Soukakou, E. (2011). Inclusion for Young Children with Disabilities: A Quarter Century of Research Perspectives. Journal of Early Intervention 33(4), 344-356. https://doi.org/10.1177/1053815111430094

OECD (2001). Starting Strong: Early Childhood Education and Care. Paris: OECD Publishing.

OECD (2012). Starting Strong III: A Quality Toolbox for Early Childhood Education and Care, OECD Publishing. Paris: OECD Publishing.

OECD (2018a). Early Learning Matters. Paris: OECD Publishing.

OECD (2018b). Education at a Glance 2018: OECD Indicators. OECD Publishing, Paris, https://doi.org/10.1787/eag-2018-en.

O'Rourke, J. (2015). Inclusive schooling: if it's so good - why is it so hard to sell?. International Journal of Inclusive Education, 19(5), 530-546, https://doi.org/10.1080/13603116.2014.954641

Park, M.-H., Dimitrov, D. M., \& Park, D.-Y. (2018). Effects of Background Variables of Early Childhood Teachers on Their Concerns About Inclusion: The Mediation Role of Confidence in Teaching. Journal of Research in Childhood Education, 32(2), 165-180. https://doi.org/10.1080/02568543.2017.1417926

Pedaste, M., Leijen, Ä., Poom-Valickis, K., \& Eisenschmidt, E. (2019). Teacher professional standards to support teacher quality and learning in Estonia. European Journal of Education, 54(3), 389-399. https://doi.org/10.1111/ejed.12346

Pelatti, C. J., Dynia, J. M., Logan, J. A. R., Justice, L. M., \& Kaderavek, J. (2016). Examining Quality in Two Preschool Settings: Publicly Funded Early Childhood Education and Inclusive Early Childhood Education Classrooms. Child Youth Care Forum, 45, 829-849. https://doi.org/10.1007/s10566-016-9359-9

Poom-Valickis, K., \& Ulla, T. (2020). Kaasava hariduse rakendamist toetavate hoiakute kujundamine õpetajakoolituse esmaõppes. Eesti Haridusteaduste Ajakiri, 8(1), 72-99. https://doi.org/10.12697/eha.2020.8.1.04

Prater, M.A. (2010). Inclusion of Students with Special Needs in General Education Classrooms. International Encyclopedia of Education (Third Edition), 721-726. https://doi.org/10.1016/B978-0-08-044894-7.01117-9

Salisbury, C. L. (1990). The Least Restrictive Environment: Understanding the Options. Policy and Practice in Early Childhood Special Education Series. Külastatud aadressil: https://eric.ed.gov/contentdelivery/servlet/ERICServlet?accno=ED340161

Schneider, C. (2015). Social participation of children and youth with disabilities in Canada, France and Germany. International Journal of Inclusive Education, 19(10), 1068-1079, https://doi.org/10.1080/13603116.2015.1037867

Stone, J. (2013). Planning for universal design for learning in the early childhood inclusion classroom: A case study. Dissertation. University of Texas. 
Soukakou, E. (2012). Measuring quality in inclusive preschool classrooms: Development and validation of the Inclusive Classroom Profile (ICP). Early Childhood Research Quarterly, 27, 478-488. http://doi.org/10.1016/j.ecresq.2011.12.003

Soukakou, E., Evangelou, M., \& Holbrooke, B. (2018). Inclusive Classroom Profile: A Pilot Study of Its Use as a Professional Development Tool. International Journal of Inclusive Education, 22(10), 1124-1135. https://doi.org/10.1080/13603116.2017.1416188

Stepaniuk, I. (2019). Inclusive education in Eastern European countries: a current state and future directions. Journal International Journal of Inclusive Education, 23(3), 328-352. https://doi.org/10.1080/13603116.2018.1430180

Sucuoğlu, B., Bakkaloğlu, H., Işcen Karasu, F., Demir, S., \& Akalin, S. (2013). Inclusive preschool teachers: their attitudes and knowledge about inclusion. International Journal of Early Childhood Special Education, 5(2), 107-128.

Sukumaran, S., Loveridge, J., \& Green, A. G. (2015). Inclusion in Malaysian integrated preschools, International Journal of Inclusive Education, 19(8), 821-844. https://doi.org/10.1080/13603116.2014.981229

Zhang, K.C. (2011). Early childhood education and special education: how well do they mix? An examination of inclusive practices in early childhood educational settings in Hong Kong, International Journal of Inclusive Education, 15(6), 683697. https://doi.org/10.1080/13603110903317676

UNESCO (2008). Education for All by 2015. Will we make it? EFA Global Monitoring Report 2008. Paris: UNESCO.

Vlachou, A., \& Fyssa, A. (2016). Inclusion in Practice: Programme Practices in Mainstream Preschool Classrooms and Associations with Context and Teacher Characteristics International Journal of Disability, Development and Education, 63(5), 529-544. https://doi.org/10.1080/1034912X.2016.1145629

Warren, S. R., Martinez, R. S., \& Sortino, L. A. (2016). Exploring the Quality Indicators of a Successful Full-Inclusion Preschool Program. Journal of Research in Childhood Education, 30(4), 540-553. https://doi.org/10.1080/02568543.2016.1214651 


\title{
A model of inclusive education in the context of Estonian preschool education: a systematic literature review
}

\author{
Pille Nelis $^{\text {al }}$, Margus Pedaste ${ }^{\mathrm{a}}$ \\ ${ }^{a}$ Institute of Education, University of Tartu
}

\section{Summary}

\section{Introduction}

The idea of inclusive education has become a key issue in the fields of education around the world (Soukakou, 2012; Vlachau \& Fyssa, 2016). Studies have shown that participation in qualitative early childhood education programmes and in the inclusive classroom has a positive effect on children's academic skills and social development (Kwon, Hong, \& Jeon, 2017; Odom, 2002; OECD, 2018a). Inclusive education is generally conceptualised as access to learning opportunities that supports the rights of all children, with and without disabilities, to participate actively in everyday activities within their communities (Prater, 2010; UNESCO, 2008). Multiple definitions of inclusive education can be found in the literature, with authors emphasising its different aspects (Kivirand, Leijen, Lepp, \& Malva, 2020). However, with various definitions offered by the literature where different aspects are emphasised, it is still unclear what are all the relevant aspects in the definition of inclusive education and thus, our study focuses on formulating a new definition.

In addition, inclusive education is a multi-dimensional issue lacking clarity about its implementation (Haug, 2017; Prater, 2010). According to the literature, there are different characteristics to be considered for implementing successful inclusive education, and the model most commonly used for this is the bioecological one developed by Bronfenbrenner and his colleagues (Love, 2018; Næsby, 2018; Odom et al., 1999). Several authors and some agencies have divided the key characteristics of inclusive education into structural features and process features (European Agency for Special Needs and Inclusive Education, 2017; Fyssa et al., 2014; Pelatti et al., 2016). Thus, there are different ways for categorising the characteristics of inclusive education and more clarity needs to be achieved in order to support the implementation of the principles of inclusive education.

Institute of Education, University of Tartu, Salme 1a, Tartu, 50103 Estonia; pille.nelis@ut.ee 
By screening all the titles of the most important educational research journals focusing on publishing systematic literature reviews and meta-analyses or research on inclusive education (Review of Educational Research, Educational Research Review and International Journal of Inclusive Education), we found only a few articles focusing on inclusive education at the early childhood education level (Botha, Kourkoutas, 2016; Capp, 2017; de Jager, 2013; Gaffney \& Wilkins, 2016; Schneider, 2015). Thus, there is a lack of systematic literature reviews on the definitions and key features of inclusive education in early childhood education that would help to understand the nature of inclusive education in all its aspects, support the implementation of inclusive education and provide a basis for comparing inclusive education in different contexts.

We aim to suggest a definition that would integrate the most important aspects provided by definitions used in the literature; operationalise the contemporary concept of inclusive education through characteristics identified in different studies; and provide a framework for applying inclusive education at the early childhood level. These aims could be achieved by using a systematic literature review, and we expect it to shed some light on the matter in order to make decisions that could guide the application of inclusive education in the current situation where the concept of inclusive education has not been operationalised clearly enough.

The following sub-goals were formulated:

1. To define inclusive education based on different approaches to inclusive education.

2. To find out the key features to implement inclusive education in the context of early childhood education.

\section{Methodology}

A systematic literature review was conducted to identify studies reporting on inclusive education in the early childhood education context. The first search in the EBSCOhost service discovered 580 sources. After removing the duplicates, 423 publications remained for the following analysis. The abstract of each article was screened to see if the article met the inclusion criteria. If insufficient information was presented in the abstract, full texts were retrieved for further examination. Following the criteria, 197 articles were selected for fulltext examination. During the examination exclusion criteria were established according to which 142 articles were excluded and 55 articles passed for further analysis. The remaining 55 articles were coded and analysed based on research questions. Qualitative inductive content analysis was used to analyse the articles. 


\section{Key findings and discussion}

It was found that inclusive education can be defined through philosophical and practical sense. The analysed articles showed that four aspects - access, belonging and membership, social integration, and human rights - could describe the philosophical sense.

In Estonia, a large proportion of children have access to education at a younger age than in other countries. In 2016, 90\% of three-year-olds participated in pre-primary education compared to the OECD average of $76 \%$ and the EU average of $82 \%$ (OECD, 2018b).

Three aspects - participation, support, and development of every child describe the practical sense of inclusion. Inclusion is achieved by ensuring meaningful participation of children and personalised support when needed to achieve the development of the child according to the child's potential. The principles of inclusive education should be reflected in strategic documents, including the curriculum. In addition, the implementation of inclusive education is supported by a shared understanding of inclusive education (Florian, 2017). The results of previous research conducted in Estonia have shown that the meaning of inclusive education is interpreted differently among specialists, teachers and education managers (Häidkind \& Oras, 2016; Kivirand et al. 2020).

As a result of our study a new definition was provided for inclusive education: an educational approach that takes into account human rights and provides all children with access to high quality education in a learning environment where children feel social integration and belongingness in their wider social network despite their special needs; it is achieved by the meaningful participation of all children and personalised support in the development of each child's full potential.

Contemporary inclusive education was operationalised by 14 categories of characteristics on five levels: child characteristics, physical inclusion, social inclusion, and psychical inclusion on the children level; teacher characteristics and classroom practices on the teacher level; family involvement and family support on the family level; school culture and structural characteristics on the institutional level; policy and legislation, cooperation, resources and funding, and monitoring and evaluation on the state level. The characteristics are described through the model where in the middle of each level is the subject who is related to the characteristics or is responsible for providing the access and ensuring the quality of the characteristics on a particular level and thereby influences the implementation of inclusive education. The model refers to responsibility on different levels and should help to implement inclusive education in early childhood education. 
The success of teaching and how a teacher copes with teaching in an inclusive environment depends on the teacher's knowledge and attitudes (Park et al., 2018). In their study, Häidkind and Oras (2016) pointed out that the attitudes of kindergarten teachers towards inclusion in Estonia were more positive than those of schoolteachers. At the same time, early childhood teachers experience difficulties in involving children with special needs (Häidkind \& Oras, 2016). Thus, kindergarten teachers should be provided with training to increase their competence in involving children with special needs.

The findings of the current study are valuable for designing curricula for improving early childhood teachers' skills of applying inclusive education. The curriculum should consider the teacher level characteristics, especially classroom practices as well as other characteristics that influence teachers' skills of applying inclusive education. Furthermore, this model should promote evaluation of the needs of teachers' professional development and implementation of inclusive education in general.

Keywords: inclusive education, early childhood education, preschool, definition, systematic review 